\title{
A case of Smith-Lemli-Opitz syndrome confirmed by molecular analysis: Review of mutation spectrum of the DHCR7 gene in Korea
}

Moon-Yeon Oh', Jun Suk Kim¹, Ja Hye Kim¹, Ja Hyang Cho ${ }^{1}$, Beom Hee Lee ${ }^{1,2}$, Gu-Hwan Kim², Jin-Ho Choi', and Han-Wook Yoo ${ }^{1,2, *}$ ${ }^{1}$ Department of Pediatrics, ${ }^{2}$ Medical Genetics Center, Asan Medical Center Children's Hospital, University of Ulsan College of Medicine, Seoul, Korea

Smith-Lemli-Opitz syndrome (SLOS) is a rare autosomal recessive disorder caused by 7-dehydrocholesterol reductase deficiency. The characteristic clinical features are syndactyly of the second and third toes, facial dysmorphism, multiple malformations, and intellectual disability. Few cases of SLOS have been reported in Korea. We observed a male patient with SLOS who presented with typical facial features, undescended testes, microcephaly, bilateral syndactyly of the second and third toes, and cardiac defects, including patent ductus arteriosus and atrial septal defect. Mutation analysis of the $D H C R 7$ gene identified compound heterozygous mutations of c.907G>A (p.Gly303Arg) and c.1055G>A (p.Arg352Gln). In a review of the literature, c.1054C>T (p.Arg352Trp) was the most common mutation reported in Far East Asian countries. This report describes the clinical features, biochemical data, molecular characteristics, and clinical outcome of a Korean patient with SLOS.

Key words: Smith-Lemli-Opitz syndrome, 7-Dehydrocholesterol reductase, DHCR7.

\section{Introduction}

Smith-Lemli-Opitz syndrome (SLOS) is a rare autosomal recessive disorder with multiple congenital anomalies. It is caused by an inborn error of cholesterol biosynthesis, which results from the deficiency of 7-dehydrocholesterol (7-DHC) reductase enzyme that converts 7-DHC to cholesterol [1-3]. The estimated incidence of SLOS ranged from 1 in 20,000 to 1 in 60,000 in the Caucasian population, and was less common in the Asian population [3]. SLOS is characterized by growth retardation, intellectual disability, and multiple malformations. The most common clinical features are facial dysmorphism (narrow forehead, epicanthal folds, ptosis, short mandible, short nose, anteverted nares, and low-set ears), syndactyly of the second and third toes, microcephaly, hypospadias, cleft palate, and postaxial polydactyly $[1,3,4]$.

Although the diagnosis of SLOS is based on elevated serum 7-DHC and low serum cholesterol levels, the serum cholesterol level can be normal in mild cases [5]. Therefore, mutation analysis of the DHCR7gene, which encodes 7-DHC reductase, is useful for confirmatory diagnosis [6].

To date, few cases of SLOS have been reported in Korea [7-12]. We recently encountered a case of SLOS where a male patient presented with typical facial dysmorphism, undescended testes, microcephaly, syndactyly, and cardiac defects, and this was

Received: 21 August 2014, Revised: 25 September 2014, Accepted: 27 September 2014, Published: 31 December 2014

${ }^{*}$ Corresponding author: Han-Wook Yoo, M.D., Ph.D.

Department of Pediatrics, Asan Medical Center Children's Hospital, University of Ulsan College of Medicine, 88 Olympic-ro 43-gil, Songpa-gu, Seoul 138736, Korea.

Tel: +82-2-3010-3374, Fax: +82-2-473-3725, E-mail: hwyoo@amc.seoul.kr

Conflict of interest: The authors have no conflicts of interest to disclose.

(ㄷ) This is an open-access article distributed under the terms of the Creative Commons Attribution Non-Commercial License (http://creativecommons.org/licenses/by-nc/3.0/) which permits unrestricted non-commercial use, distribution, and reproduction in any medium, provided the original work is properly cited.

(c) Copyright 2014 by the Korean Society of Medical Genetics 


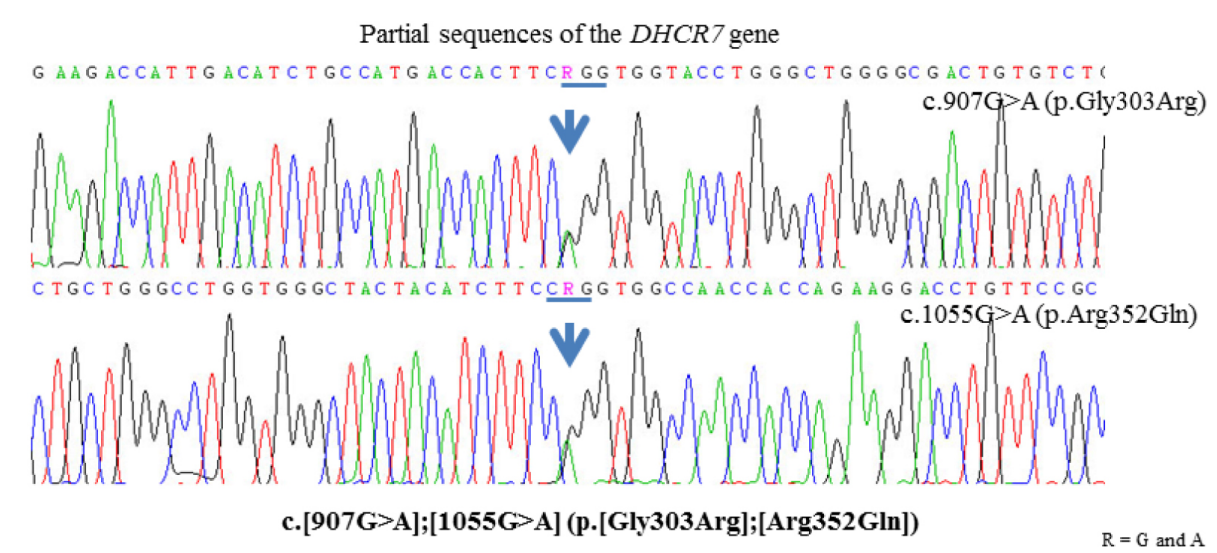

Fig. 1. Direct sequencing of the $D H C R 7$ gene. Compound heterozygous mutations of $c .907 \mathrm{G}>\mathrm{A}$ (p.Gly303Arg) and c.1055G >A (p.Arg352GIn) c. $[907 \mathrm{G}>\mathrm{A}] ;[1055 \mathrm{G}>\mathrm{A}]($ p. [Gly303Arg];[Arg352GIn]) $\mathrm{R}=\mathrm{G}$ and $\mathrm{A}$ were identified, as indicated in blue.

confirmed by molecular analysis of the DHCR7 gene. Here, we describe the clinical features, biochemical data, and molecular characteristics of this case, with a review of the literature.

\section{Case}

The patient was born at 40 weeks of gestation, by cesarean section because of fetal distress and placental abruption. The patient weighed 2,700 $\mathrm{g}(-1.55$ standard deviation score [SDS]) at birth and was the first child born to nonconsanguineous parents. As the triple marker test was abnormal at 16 weeks of gestation, amniocentesis was carried out, and the karyotype was 46,XY.

At birth, the patient displayed transient tachypnea and weak crying; this improved spontaneously after several days. Low-set and large ears, bilateral syndactyly of the second and third toes, a grade 2 systolic murmur at the left sternal border, developmental dysplasia of both hips, and ambiguous genitalia with hypospadias were noted. Patent ductus arteriosus (diameter, $1.5 \mathrm{~mm}$ ) and a secundum atrial septal defect (ASD; diameter, $6 \mathrm{~mm}$ ) were identified by echocardiography. Pelvic ultrasonography revealed the right testis in the peritoneum and left testis in the inguinal canal, without a uterus or ovaries. Auditory evoked potential measurements showed a sensorineural hearing defect in both ears (70 dB discrepancy in the right, $100 \mathrm{~dB}$ discrepancy in the left). At the age of 3 months, the patient was hospitalized because of pneumonia and pulmonary edema. Upon followup echocardiography, an almost common atrium, due to a large ASD (diameter, $>8 \mathrm{~mm}$ ), and a dilated right ventricle were observed. The patient was treated with intravenous antibiotics and diuretics.

The patient was referred to our institute for evaluation of multiple congenital anomalies at 1.6 years of age, when his height, weight, and head circumference were $77.6 \mathrm{~cm}(-1.81$ SDS), $6.3 \mathrm{~kg}(-5.57 \mathrm{SDS})$, and $40.5 \mathrm{~cm}(-4.50 \mathrm{SDS})$, respectively. He manifested bilateral Y-shaped partial syndactyly of the second and third toes, micropenis, bilateral undescended testes, and facial dysmorphism such as bilateral epicanthic folds, large ears, and strabismus. The serum cholesterol level was $17 \mathrm{mg} / \mathrm{dL}$ (normal range, 45-182 mg/dL). Subsequently, he underwent ASD closure surgery using fresh autologous pericardium for a large ASD (diameter, $17.1 \mathrm{~mm}$ ). Direct sequencing of the DHCR7gene, using genomic DNA isolated from peripheral blood leukocytes, identified compound heterozygous mutations of c.907G $>A$ (p.Gly303Arg) and c.1055G>A (p.Arg352GIn) (Fig. 1), which were already reported to be pathogenic [13]. Mutation analysis of the patient's parents was not carried out.

\section{Discussion}

This study described a case of SLOS, which was confirmed by molecular analysis of the DHCR7gene. Two missense mutations in our case, p.Gly303Arg and p.Arg352GIn, were previously reported to be pathogenic in Japanese SLOS patients [13]. SLOS was first described in 1964 by David Smith, Luc Lemli, and John Opitz, as distinctive facial appearance, microcephaly, broad alveolar ridges, hypospadias, severe feeding disorder, and developmental delay [2]. Tint et al. [14] reported that SLOS patients had an increased plasma concentration of 7-DHC, suggesting a deficiency in the 7-DHC reductase the final step of the cholesterol biosynthesis pathway. In 1998, it was discovered that defects in the DHCR7 gene located on chromosome $11 \mathrm{q} 13.4$ cause SLOS [6].

The DHCR7 gene contains 9 exons and 8 introns within 


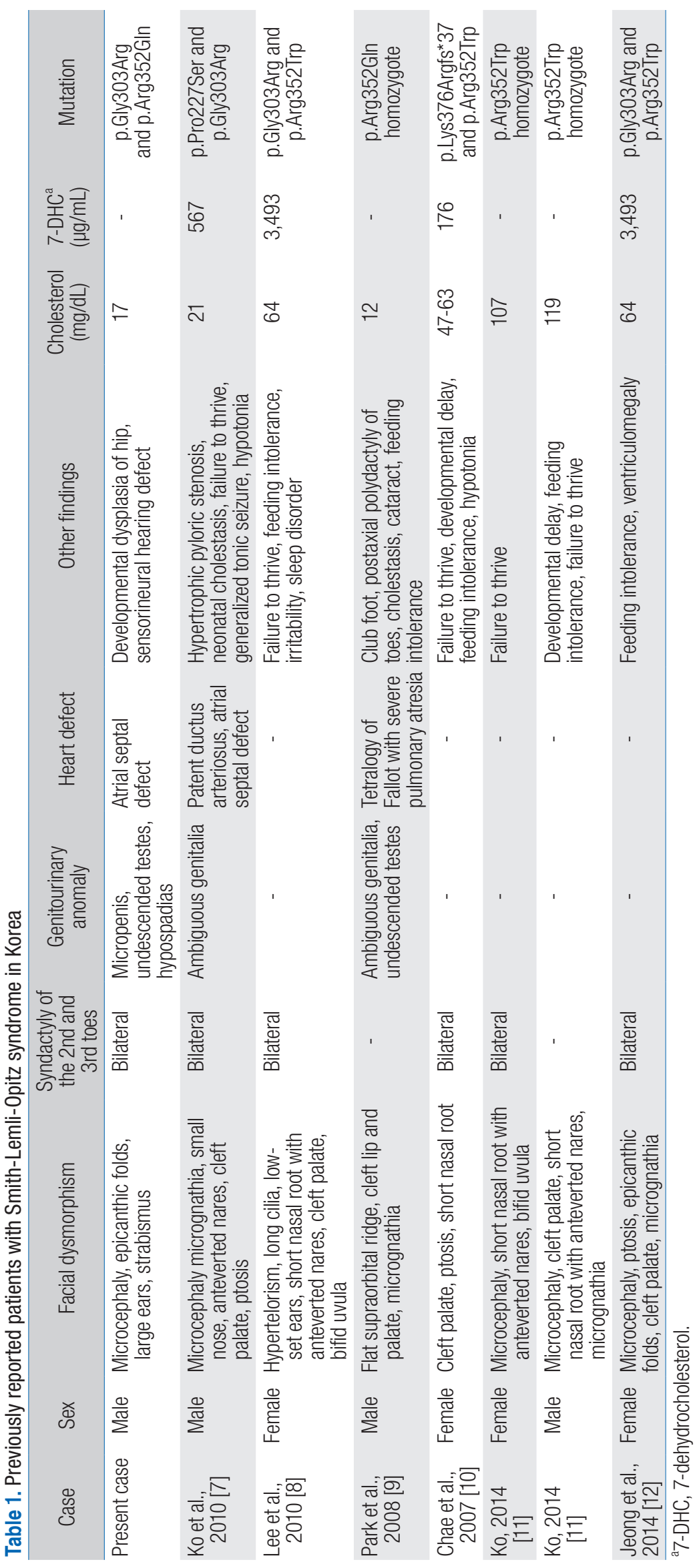


14,100 base pairs. The 7-DHC reductase is encoded by exons 3-9 [15]. Thus far, 165 mutations in the DHCR7 gene have been reported in the Human Gene Mutation Database (http://www. hgmd.org/), and the majority are missense mutations. Among these, the splice-site mutation c.832-1G>C (IVS8-1G>C) is the most common (allele frequency: $\sim 30 \%$ ) in Caucasians $[16,17]$. In contrast, there have been reports of the c.832$1 \mathrm{G}>\mathrm{C}$ mutation in Korean patients with SLOS [7-12]. Thus far, 8 cases of SLOS have been reported in Korea, including the present case [7-12]. The clinical and molecular findings of previously reported cases of Korean patients with SLOS are summarized in Table 1. All cases were confirmed by mutation analysis of the DHCR7gene. Among these cases, the c.1054C>T (p.Arg352Trp) mutation was the most common (43.75\%, 7/16), followed by c.907G >A (p.Gly303Arg) (25.00\%, 4/16), c. 1055G>A (p.Arg352GIn) (18.75\%, 3/16), c.679C >T (p.Pro227Ser) (6.25\%, 1/16), and c. 1128delA (p.Leu376Argfs*37) (6.3\%, 1/16) [7-12]. The c. $1055 \mathrm{G}>\mathrm{A}$ (p.Arg352GIn) mutation is the most common mutation in Japanese patients [13], whereas the p.Arg352GIn mutation has been reported in a few Caucasian patients [16]. Overall, there is a difference in the mutation spectrum of the DHCR7 gene according to ethnicity, suggesting a founder effect.

Although it is difficult to establish a correlation between genotype and phenotype, some genotypes are known to cause a severe phenotype. Witsch-Baumgartner et al. [15] grouped mutations into 4 classes: nonsense and splice-site mutations resulting in putative null alleles, missense mutations in the transmembrane domain (TM), mutations in the fourth cytoplasmic loop (4L), and mutations in the carboxy-terminal endoplasmic reticulum domain (CT). They reported that patients with null and $4 \mathrm{~L}$ mutations had severe clinical phenotypes, while patients with TM and CT mutations had mild clinical phenotypes. Both the c.907G>A (p.Gly303Arg) and c.1055G>A (p.Arg352GIn) mutations in our case are located in the TM region, indicating a mild clinical phenotype.

Common clinical findings in SLOS were second and third toe syndactyly, developmental delay, microcephaly, and postnatal growth retardation; each finding was observed in at least 80\% of SLOS patients. Approximately 50-60\% of SLOS patients had genital anomalies and congenital heart defects, including the case reported here $[3,18]$. The serum concentration of cholesterol is helpful for the diagnosis of SLOS, because most affected infants have hypocholesterolemia $(<40 \mathrm{mg} / \mathrm{dL}$ ). However, the serum cholesterol value can be normal in approximately $10 \%$ of SLOS patients [5]. Therefore, high serum concentration of 7-DHC is an important clue for the diagnosis of SLOS [3], and mutation analysis of the DHCR7gene is helpful for confirmatory diagnosis.

Although therapeutic options for SLOS are limited, cholesterol supplementation might improve clinical symptoms such as irritability, hyperactivity, sleep disorders, and growth retardation. Supplementation of dietary cholesterol not only raises blood cholesterol to normal levels, but also often prevents the accumulation of 7-DHC via feedback inhibition. The estimated daily cholesterol requirement during infancy is $30-40 \mathrm{mg} \cdot \mathrm{kg}^{-1} \cdot$ day $^{-1}$, which decreases to $10 \mathrm{mg} \cdot \mathrm{kg}^{-1} \cdot$ day $^{-1}$ in adults; experimental treatment protocols included $30 \mathrm{mg} \cdot \mathrm{kg}^{-1} \cdot \mathrm{day}^{-1}$ of egg yolk or 150-300 $\mathrm{mg} \cdot \mathrm{kg}^{-1} \cdot$ day $^{-1}$ of cholesterol suspension $[3,19]$.

Low maternal concentration of unconjugated estriol could suggest the possibility of SLOS [18]. Fetal ultrasound findings of intrauterine growth retardation; major malformation of the brain, heart, kidneys, or limbs; and ambiguous genitalia may be helpful for prenatal diagnosis of SLOS. When SLOS is suspected, the elevated 7-DHC and/or decreased cholesterol level in the amniotic fluid is a helpful biomarker for diagnosis. In addition, molecular sequencing of the DHCR7gene, using chorionic villus tissue or amniocytes, can be considered for prenatal diagnosis $[1,5,20]$.

In conclusion, we have reported the case of a patient with SLOS who carried heterozygous mutations of c. $907 \mathrm{G}>\mathrm{A}$ (p.Gly303Arg) and c.1055G>A (p.Arg352GIn) in the DHCR7 gene, and described the mutation spectrum of DHCR7 in Korea via a review of available literature. As the clinical features and biochemical findings of SLOS are variable, molecular analysis of the DHCR7 gene is useful for confirmation of its diagnosis.

\section{References}

1. Nowaczyk MJ, Irons MB. Smith-Lemli-Opitz syndrome: phenotype, natural history, and epidemiology. Am J Med Genet C Semin Med Genet 2012;160C:250-62.

2. Smith DW, Lemli L, Opitz JM. A newly recognized syndrome of multiple congenital anomalies. J Pediatr 1964;64:210-7.

3. Kelley RI, Hennekam RC. The Smith-Lemli-Opitz syndrome. J Med Genet 2000;37:321-35.

4. Porter FD. RSH/Smith-Lemli-Opitz syndrome: a multiple congenital anomaly/mental retardation syndrome due to an inborn error of cholesterol biosynthesis. Mol Genet Metab 2000;71:163-74.

5. Kelley RI. Diagnosis of Smith-Lemli-Opitz syndrome by gas chromatography/mass spectrometry of 7-dehydrocholesterol in 
plasma, amniotic fluid and cultured skin fibroblasts. Clin Chim Acta 1995;236:45-58.

6. Fitzky BU, Witsch-Baumgartner M, Erdel M, Lee JN, Paik YK,

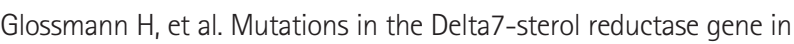
patients with the Smith-Lemli-Opitz syndrome. Proc Natl Acad Sci U S A 1998:95:8181-6.

7. Ko JS, Choi BS, Seo JK, Shin JY, Chae JH, Kang GH, et al. A novel DHCR7 mutation in a Smith-Lemli-Opitz syndrome infant presenting with neonatal cholestasis. J Korean Med Sci 2010;25:159-62.

8. Lee HJ, Lee JH, Lee JS, Choe YH. The Smith-Lemli-Opitz syndrome with a G303R/R352W mutation: in an extremely irritable child responsive to cholesterol supplementation. Genes Genomic 2010;32:9-12.

9. Park MR, Ko JM, Cheon CK, Kim GH, Yoo HW. A case of Smith-LemliOpitz syndrome diagnosed by identification of mutations in the 7-dehydrocholesterol reductase (DHCR7) gene. Korean J Pediatr 2008;51:1236-40.

10. Chae JH, Kim KJ, Hwang YS, Ki CS, Kim JW. Identification of a novel DHCR7 mutation in a Korean patient with Smith-Lemli-Opitz syndrome. J Child Neurol 2007;22:1297-300.

11. Ko JM. Clinical and molecular genetic characteristics of Korean patients with Smith-Lemli-Opitz syndrome: a report of new patients with a literature review. J Korean Soc Inher Metab Dis 2014;14:48-53.

12. Jeong YJ, Huh R, Kwun YH, Lee JE, Cho SY, Ki CS, et al. A case of Smith-Lemli-Opitz syndrome in DHCR7 mutation. J Korean Soc Inher Metab Dis 2014;14:60-65.

13. Matsumoto $Y$, Morishima $K_{1}$ Honda $A$, Watabe $S$, Yamamoto $M$, Hara
M, et al. R3520 mutation of the DHCR7 gene is common among Japanese Smith-Lemli-Opitz syndrome patients. J Hum Genet 2005;50:353-6.

14. Tint $G S$, Irons $M$, Elias ER, Batta $A K$, Frieden $R$, Chen $T S$, et al. Defective cholesterol biosynthesis associated with the Smith-Lemli-Opitz syndrome. N Engl J Med 1994;330:107-13.

15. Witsch-Baumgartner $M$, Löffler J, Utermann G. Mutations in the human DHCR7 gene. Hum Mutat 2001;17:172-82.

16. Waterham HR, Hennekam RC. Mutational spectrum of SmithLemli-Opitz syndrome. Am J Med Genet C Semin Med Genet 2012;160C:263-84.

17. $Y u H$, Tint $G S$, Salen $G$, Patel SB. Detection of a common mutation in the RSH or Smith-Lemli-Opitz syndrome by a PCR-RFLP assay: IVS8$\mathrm{G}-->\mathrm{C}$ is found in over sixty percent of US propositi. Am J Med Genet 2000;90:347-50.

18. Jira PE, Waterham HR, Wanders RJ, Smeitink JA, Sengers RC, Wevers RA. Smith-Lemli-Opitz syndrome and the DHCR7 gene. Ann Hum Genet 2003;67:269-80.

19. Svoboda MD, Christie JM, Eroglu Y, Freeman KA, Steiner RD. Treatment of Smith-Lemli-Opitz syndrome and other sterol disorders. Am J Med Genet C Semin Med Genet 2012;160C:285-94.

20. Abuelo DN, Tint GS, Kelley R, Batta AK, Shefer S, Salen G. Prenatal detection of the cholesterol biosynthetic defect in the Smith-LemliOpitz syndrome by the analysis of amniotic fluid sterols. Am J Med Genet 1995;56:281-5. 